\title{
Communication about scientific uncertainty: how scientists and science journalists deal with uncertainties in nanoparticle research
}

Ilona Heidmann ${ }^{* \dagger}$ and Jutta Milde ${ }^{\dagger}$

\begin{abstract}
Background: 'There is a high level of scientific uncertainty in nanoparticle research' is often stated in the scientific literature, e.g., concerning the environmental fate of nanoparticles. Knowing more about these uncertainties and the communication about it in scientific literature and mass media might be of interest to other scientists and experts. Due to this, we compare the current state of scientific knowledge about scientific uncertainty through the example of environmental nanoparticle research with the media coverage in the field of nanotechnologies.

Results: In research and review papers, scientific uncertainties, sources, and consequences are mentioned with different foci and to a different extent. In research papers, the authors focus on the certainty of specific results, whereas in review papers, the uncertainties due to a general lack of data are emphasized and the sources and consequences are discussed. The content analysis of the media coverage shows that nanotechnology is often framed as rather certain, and only one-third of the reports deal with scientific uncertainties. Furthermore, there is a strong relationship between the representations of scientific uncertainty and risks. Environmental issues are seldom mentioned.

Conclusions: Scientific uncertainties, sources, and consequences have been most widely discussed in the review papers. Research papers and mass media tend to emphasize more the certainty of their results or topics. Neither the broad spectrum nor any specifications of uncertainties have been communicated. This indicates that there has been no effective dialogue over scientific uncertainty with the public so far.
\end{abstract}

Keywords: Scientific uncertainty; Nanoparticles; Environment; Media coverage; Nanotechnology

\section{Background}

The developments in the fields of nanotechnologies are increasing rapidly and over broad ranges. As a result, a large number of different nanoparticles have been synthesized for a wide range of applications. Due to their increasing production [1] and use in consumer products such as, e.g., cosmetics, groceries, cleansers, sprays, and paints, a release into the environment is expected [2-8]. Despite over 10 years of intensive research, certain conclusions regarding the fate of nanoparticles in the environment are difficult to draw [9]. 'There is a high level of uncertainty in the research concerning the fate of nanoparticles in the environment' is often stated [10].

\footnotetext{
* Correspondence: heidmann@uni-landau.de

${ }^{\dagger}$ Equal contributors

Interdisciplinary Research Group for Environmental Studies, University of Koblenz-Landau, Fortstr. 7, Landau 76829, Germany
}

The fast-growing area of research concerning the environmental fate of nanoparticles and the high level of uncertainty creates a big challenge for describing clearly the recent state of the current scientific knowledge [11]. Knowing uncertainties and their kind, sources, and consequences would help in assessing the reliability, relevance, and adequacy of the available data and enable better acting under uncertainty, e.g., for political or scientific decisions concerning prioritizing research or regulation. There exist first descriptions of the uncertainty of nanoparticle fate and effects in the environment including investigations of measurement uncertainties in characterizing nanoparticles with different methods $[12,13]$ and scientific research in the field of the environmental fate and effects of nanoparticles [14], but no studies could be found focusing on uncertainties in the 
nanoparticle environmental fate research discussed in the scientific literature.

While discussion about scientific uncertainty is an integral part of scientific work and researchers are accustomed to dealing with it, for many laypersons, those debates are often incomprehensible. But it might be important for laypersons to evaluate scientific innovations to make personal (e.g., about healthcare) or political decisions about new or controversial issues. This applies to the academic field of nanotechnology as well as to other scientific fields. For laypersons, mass media are one of the main sources of scientific information $[15,16]$. Previous studies showed that their perceptions and attitudes towards nanotechnology may depend on the way journalists communicate scientific uncertainties about harmful effects of nanoparticles on the environment and human health [17-20]. Hence, science journalists have an important role in the communication process about nanotechnology because they have to deal with contradictory information or uncertain scientific explanations.

Investigations about the media coverage of nanotechnology have been in progress since 2005. Most of them have been long-term studies over a period of 10 years, and the majority of content analysis includes only the press coverage about nanotechnology [21-30]. Further, media such as online media or magazines have seldom been considered $[31,32]$ and there has been a lack of investigations of TV science coverage. The content analysis showed that reports about fundamental research have dominated media coverage $[23,31]$. The scientific progress is frequently emphasized, and the research context and scientific facts are most frequently mentioned [24,25,28,30,33,34]. Furthermore, the research about nanotechnology is often presented as rather certain: media coverage emphasizes positive aspects and benefits and scientific evidence is presented as strong $[24,27,33]$. Scientific uncertainty is seldom mentioned $[23,31]$ and only with regard to risks to the environment or human health $[24,35]$. Usually, this is justified by a lack of data [36]. However, risks are often not described in detail [33,37]. Hence, it appears that mass media emphasized the certainty of nanotechnology, whereas any uncertainty was mentioned only in passing.

Against this background, the motivation of our study is to encourage discussion about scientific uncertainty and its representation in mass media. Knowing about the differences between communication channels - publishing of reproducible data for experts in a peer-reviewed system on the one hand and of 'stories' for laymen in an editorial system on the other - we compare the output, differences, and congruence of both concerning scientific uncertainty. Therefore, our objectives are to analyze the scientific uncertainties in nanoparticle research through the example of the 'environmental fate of nanoparticles' and to evaluate the representation of scientific uncertainties in mass media in the field of nanotechnology in order to analyze to what extent mass media have captured scientific uncertainties in general and environmental issues in particular. Firstly, we characterize the uncertainties in the scientific literature (research and review papers) concerning selected aspects of the environmental fate of nanoparticles and identify the sources and consequences. For the characterization of uncertainties in research papers, the field 'transport of metal oxide nanoparticles in porous media' was selected. This restriction was made in order to enable comparison of the mentioned uncertainties of one field of research. The topic was chosen because mobility is one of the most important factors that determine the fate and effects of a substance in the environment. Secondly, we analyze the representation of scientific uncertainty of nanotechnology in the media. We investigate the whole range of nanotechnology issues to evaluate the coverage patterns about the representation of scientific uncertainty. The findings enable us to identify how journalists cover scientific uncertainties and to determine important topics and actors. Finally, we compare the results of the media content analysis with the mentioned uncertainties in scientific literature.

Uncertainty can be defined in many different ways and from many different perspectives. Scientific uncertainty arises when results are, e.g., not yet validated, contradictory, inconsistent, or not reproducible. This understanding of scientific uncertainty is assumed for scientists as well as for science journalists. In order to characterize the uncertainties in scientific literature, according to Heidmann [38], two different perspectives were further distinguished: (a) the uncertainties related to basic research like measuring and method uncertainties and conflicting results due to not yet validated, contradictory, inconsistent, or not reproducible data, and (b) the uncertainties related to applied research questions such as, e.g., in risk assessment by discussing the results in a broader context rather than a single, explicit research question like transferability of model data or data from model systems to environmental systems, the applicability of models, a general or specific lack of reliable data, or uncertainties in scaling issues, e.g., due to spatial heterogeneity. In this context, the following research questions are addressed: (1) What kinds of uncertainties are discussed in the scientific literature represented by peer-reviewed research and review papers in the field of the environmental fate of nanoparticles? (2) What are the sources and consequences of these scientific uncertainties? (3) Are there variations in the discussion of uncertainties in kind and extent between research and review papers?

To analyze the representation of scientific uncertainty of nanotechnology in the media and to determine important topics and actors, a content analysis of science media coverage was conducted. As shown, the majority of content analysis includes only press coverage about nanotechnology. There is still a lack of investigations with respect 
to other media such as TV. These investigations are also important because in Europe, notably in Germany, TV is the most popular medium for science information [39]. Hence, in this study, we also analyze TV science magazines as well as newspapers and science journals. This enables us to examine a broader range of media coverage. Furthermore, it makes intermedial comparisons possible. This is interesting because journalistic aims can differ in different media: newspapers often cover current scientific topics with political links or scientific events such as prize giving on a daily basis, whereas TV science magazines and science journals often report background information and explanations about scientific topics. Therefore, the research questions for the media analysis are as follows: (4) How can the coverage patterns about scientific uncertainty and nanotechnology be characterized? (5) What role do environmental issues play in media coverage in particular? (6) Do the coverage patterns vary in different types of media? Finally, comparing the results of the media content analysis with the mentioned uncertainties in scientific literature, the following questions are addressed: (7) How can the discussion of scientific uncertainties be characterized? (8) Does media coverage represent any of the discussion on scientific uncertainty we identified in the scientific literature about the environmental fate of nanoparticles?

\section{Results and discussion}

\section{Uncertainties in research papers}

The basis for the evaluation of scientific uncertainties in research papers concerning the environmental fate of nanoparticles was an analysis of the field of knowledge on the selected aspect 'transport of metal oxide nanoparticles in porous media' [38]. The reasons for this restriction are stated in the 'Methods' section. A literature search was conducted and 13 research papers were selected for the meta-analysis (see Table 1). Certain knowledge, known uncertainties, and knowledge gaps in the chosen topic were analyzed, and the corresponding scientific uncertainties were identified and categorized as discussed above [38].

The uncertainties discussed by the authors themselves in the selected research papers are summarized in Table 2. The mentioned uncertainties of their own research could be found mainly in the Discussion and Conclusion sections. In five studies (38\%), uncertainties related to basic research were discussed. These are measuring uncertainties related to size determination by DLS and NTA, conflicting results of studies with different nanoparticles, and method uncertainties. More often, by $85 \%$ of the authors (11 studies), uncertainties related to applied research were considered, mostly discussed in the conclusions or the sections dealing with environmental implications. Most of the authors discussed the transferability of the results to environmental conditions with different foci. Because most studies were conducted in the absence of natural organic matter, minerals other than silicium dioxide, smaller grain sizes, or secondary pore systems which may all affect the transport of nanoparticles in porous media, the transferability of these data from model systems to environmental systems is questionable [38]. A good half of the authors mentioned or discussed this uncertainty in their papers. The transferability of the results to other nanoparticles and the applicability of transport models were occasionally mentioned. The term 'uncertainty' itself was rarely mentioned. Knowledge gaps, such as the unknown surface characteristics of released nanoparticles and the unknown transformation and aging

Table 1 Selected peer-reviewed research articles on the topic transport of metal oxide nanoparticles in porous media

\begin{tabular}{|c|c|c|}
\hline $\begin{array}{l}\text { First author } \\
\text { [reference] }\end{array}$ & Year & Title \\
\hline Ben-Moshe [40] & 2010 & Transport of metal oxide nanoparticles in saturated porous media \\
\hline Chen [41] & 2011 & $\begin{array}{l}\text { Transport and retention of } \mathrm{TiO}_{2} \text { rutile nanoparticles in saturated porous media under low-ionic-strength conditions: } \\
\text { measurements and mechanisms }\end{array}$ \\
\hline Chowdhury [42] & 2011 & Mechanisms of $\mathrm{TiO}_{2}$ nanoparticle transport in porous media: role of solution chemistry, nanoparticle concentration, and flow rate \\
\hline Fang [43] & 2009 & Stability of titania nanoparticles in soil suspensions and transport in saturated homogeneous soil columns \\
\hline Godinez [44] & 2011 & Aggregation and transport of nano- $\mathrm{TiO}_{2}$ in saturated porous media: effects of $\mathrm{pH}$, surfactants and flow velocity \\
\hline Jiang [45] & 2012 & Transport and deposition of ZnO nanoparticles in saturated porous media \\
\hline Joo [46] & 2009 & $\begin{array}{l}\text { Influence of carboxymethyl cellulose for the transport of titanium dioxide nanoparticles in clean silica and } \\
\text { mineral-coated sands }\end{array}$ \\
\hline Kanel [47] & 2011 & Influence of pH on the transport of nanoscale zinc oxide in saturated porous media \\
\hline Lecoanet [48] & 2004 & Laboratory assessment of the mobility of nanomaterials in porous media \\
\hline Li [49] & 2011 & Transport and deposition of $\mathrm{CeO}_{2}$ nanoparticles in water-saturated porous media \\
\hline Petosa $[50]$ & 2012 & Transport of two metal oxide nanoparticles in saturated granular porous media: role of water chemistry and particle coating \\
\hline Solovitch [51] & 2010 & Concurrent aggregation and deposition of $\mathrm{TiO}_{2}$ nanoparticles in a sandy porous media \\
\hline Zhao [52] & 2012 & Transport and retention behavior of $\mathrm{ZnO}$ nanoparticles in two natural soils: effect of surface coating and soil composition \\
\hline
\end{tabular}


Table 2 Mentioned uncertainties in 13 selected research papers concerning their own research

\begin{tabular}{ll}
\hline Uncertainty & \multicolumn{1}{c}{ Mentioned specification (quantity) } \\
\hline Measurement uncertainties & Size (2) \\
Conflicting results & Nanoparticles different in size, shape, and type (3); different solution chemistry (1) \\
Method uncertainty & - \\
Lack of data & Without specification (4); due to the presence of organic molecules (3); preferential pathways (2); \\
Transferability to environment & variety of minerals and sizes (2); high variability (1) \\
Transferability to other nanoparticles & Type (2) \\
Applicability of models & Transport models (1) \\
Knowledge gaps & -
\end{tabular}

under environmental conditions, were not discussed explicitly in the selected studies.

\section{Uncertainties in review papers}

The uncertainties in review papers were characterized by a meta-analysis of nine selected reviews concerning the environmental fate of nanoparticles (see Table 3). Therefore, these articles were carefully screened for mentioned uncertainties concerning the fate of nanoparticles in the environment, and these statements were classified according to the different perspectives of uncertainties, just as for the research papers.

The mentioned uncertainties in the selected review papers are summarized in Table 4. Because the selected review articles cover a far broader issue and summarize, analyze, and discuss the current state of knowledge of previously published research, many more uncertainties and knowledge gaps were discussed in more detail compared with the discussion in the research papers. Uncertainties related to basic research as categorized were discussed by almost all authors (in eight out of nine studies, 89\%). The absence of adequate analytical methods was categorized as measurement uncertainties and was discussed by a good half of the authors (five studies, 56\%). Conflicting results were discussed by almost half of the authors (four studies, $44 \%)$, e.g., conflicting results of varying nanoparticles (e.g., in size, shape, crystallinity, or coating) of the same type, conflicting results of toxicology studies, effects of organic matter on nanoparticle stability, and high variations in modeled data were mentioned. In most reviews (six studies, 67\%), method uncertainty was also referred to. The lack of standard methods and reference materials leads to different sampling, measuring, modeling, and separation procedures, which may affect the characteristics of the nanoparticles differently and lead to diverse and incomparable results. It was also reported that different parameters were determined, which makes comparisons of results even more difficult.

In the selected review papers, the most discussed uncertainty related to applied research was the general lack of reliable, comparable, validated, or just any data concerning nearly all aspects of engineered nanoparticles in the environment. This kind of uncertainty was pointed out in all reviews (100\% of the authors) several times and was not discussed in the research papers. The most frequently mentioned aspects were more general aspects such as the

Table 3 Selected peer-reviewed review articles on the fate and behavior of nanoparticles in the environment

\begin{tabular}{|c|c|c|}
\hline $\begin{array}{l}\text { First author } \\
\text { [reference] }\end{array}$ & Year & Title \\
\hline Aschberger [53] & 2011 & $\begin{array}{l}\text { Analysis of currently available data for characterizing the risk of engineered nanomaterials to the environment and } \\
\text { human health - lessons learned from four case studies }\end{array}$ \\
\hline Christian [54] & 2008 & Nanoparticles: structure, properties, preparation and behavior in environmental media \\
\hline Farre [55] & 2011 & Analysis and assessment of the occurrence, the fate and the behavior of nanomaterials in the environment \\
\hline Klaine $[56]$ & 2008 & Nanomaterials in the environment: behavior, fate, bioavailability, and effects \\
\hline Lin [57] & 2010 & Fate and transport of engineered nanomaterials in the environment \\
\hline Lowry [9] & 2010 & Environmental occurrences, behavior, fate, and ecological effects of nanomaterials: an introduction to the special series \\
\hline Mudunkotuwa [58] & 2011 & $\begin{array}{l}\text { The devil is in the details (or the surface): impact of surface structure and surface energetics on understanding the } \\
\text { behavior of nanomaterials in the environment }\end{array}$ \\
\hline Nowack [59] & 2007 & Occurrence, behavior and effects of nanoparticles in the environment \\
\hline Peralta-Videa [60] & 2011 & Nanomaterials and the environment: a review for the biennium 2008-2010 \\
\hline
\end{tabular}


Table 4 Mentioned uncertainties in selected review papers

\begin{tabular}{|c|c|}
\hline Uncertainties & Specification (quantity) \\
\hline Measurement uncertainties & No adequate analytical methods (5) \\
\hline Conflicting results & $\begin{array}{l}\text { Toxicity studies (2); variability in size, shape, crystallinity, and coatings (2); low amount of data (1); effect of DOM on } \\
\text { stability (1); size effect on transport in porous media (1); modeled data (1) }\end{array}$ \\
\hline Method uncertainty & No standardized methods and reference materials (6); different/poor characterization (2); risk assessment (2) \\
\hline Lack of data & $\begin{array}{l}\text { Fate (8) and behavior (7) in environmental systems and many specified mechanisms (9); interactions with natural } \\
\text { components and contaminants and their effects (5); impact of released nanomaterials on the environment/ecosystems } \\
\text { (4); effects of coatings or organic matter on behavior and effects (3); correlation of ENM properties with respect to } \\
\text { similar effects (2); different special issues related to fate and effects (8) }\end{array}$ \\
\hline $\begin{array}{l}\text { Transferability to } \\
\text { environment }\end{array}$ & Toxicity test (3) \\
\hline $\begin{array}{l}\text { Transferability to other } \\
\text { nanoparticles }\end{array}$ & Variability in size, shape, crystallinity, and coatings (2) \\
\hline Applicability of models & DLVO and filtration theories (3); conventional ecotoxicity tests (3); size dependence of dissolution (2) \\
\hline Knowledge gap & $\begin{array}{l}\text { Quantitative data on environmental concentration (4); form, route, and mass of released nanomaterials (3); behavior at } \\
\text { environmentally relevant concentrations and forms (1); production volumes and types (1); fate of embedded } \\
\text { nanomaterials (1); surface structure, characteristics, and energetics (1) }\end{array}$ \\
\hline
\end{tabular}

DLVO Derjaguin, Landau, Verwey, and Overbeek theory.

fate, behavior, environmental concentration, (eco)toxicity, and mobility of nanoparticles in the environment. Furthermore, the lack of data concerning the impact of released nanoparticles on the environmental system and human health as well as the lack of data concerning exposure and risk assessment and life cycle assessment was discussed as well as many more specific aspects. The transferability of results to environmental conditions was discussed by a third of the authors (three studies, 33\%), which was less than in the research papers, and here in relation to toxicity tests. The transferability of results to other nanoparticles was mentioned concerning variations in size, shape, crystallinity, or coatings of the same type of nanoparticle by two authors (two studies, 22\%). The applicability of models was discussed more often (five studies, 56\%): the application of the Derjaguin, Landau, Verwey, and Overbeek theory about colloidal stability and the filtration theory, the concept of size dependence of dissolution, toxicity tests, and the risk assessment under REACH were mentioned as being questionable.

The border between uncertain knowledge and knowledge gaps seemed to be fluent. In some reviews, one aspect was found under the term 'knowledge gap'; in others it is stated that there are at least a few data. A topic was categorized as a knowledge gap if in none of the reviews any studies with concrete results concerning this issue were mentioned, and 67\% (six studies) of the authors discussed such knowledge gaps in contrast to none of the authors in the research papers. As knowledge gaps, the form, route, and mass of released nanoparticles, the fate of embedded nanoparticles, and their behavior at environmentally relevant concentrations and in environmentally relevant forms were mentioned.

\section{Sources and consequences of scientific uncertainties and knowledge gaps}

Sources and consequences of uncertainties concerning the environmental fate of nanoparticles were discussed in review but not in research papers. The main source of these uncertainties and knowledge gaps is caused by the lack of available analytical methods to separate, characterize, and detect engineered nanoparticles in environmental media at environmental concentrations [54,56,59-61]. One of the biggest challenges is to separate and characterize the small amount of engineered nanoparticles in environmental matrices, which contain high amounts of highly heterogenic natural nanoparticles [62]. Because of the lack of analytical methods, the form of nanoparticles at release and the surface properties transformed and aged in the environment are currently not known $[8,56,60]$. Therefore, one important factor of the fate of nanoparticles in the environment, the exact surface properties, and the aggregation state is still unclear [58], and the characteristics of the chosen bare or coated nanoparticles may not be relevant under environmental conditions [8]. This source of uncertainty is also relevant for other fields in environmental nanoparticle research, e.g., ecotoxicology. Also the nanoparticles (with or without coatings) which were chosen for toxicity tests may not be relevant under environmental conditions. Another problem in toxicity tests is caused by the high concentrations of salts and nanoparticles used in the test: this may induce aggregation of the particles, which may alter their behavior towards the test organisms. As consequences of these uncertainties and knowledge gaps, quantitative risk assessment, regulation, or management concerning engineered nanoparticles is still based on modeling data or studies in model systems, the 
transferability of which to environmental conditions is questionable as discussed above $[9,53,56,60]$.

\section{Uncertainties in mass media}

In order to answer research questions 4 to 6 , we investigate the amount of coverage about scientific uncertainty and the results of a cluster analysis will be presented. An overview of the clusters is given in Table 5 .

\section{Amount of coverage about scientific uncertainty and environmental issues}

The analysis shows that reports about the applications of nanotechnology dominate the media coverage. Furthermore, nanotechnology is most often represented as rather certain and the media coverage emphasizes positive aspects and benefits.

Only about one-third of the media coverage we investigated deals with scientific uncertainty (28\%). In particular, the representation of scientific uncertainty concerns the topics 'basic research' (23\%), 'nanomedicine' (21\%), and 'nanotechnology policy' (16\%), or it relates to media contributions, which give an overview about the nanotechnology field (19\%), whereas environmental issues such as the environmental fate of nanoparticles or environmental risk assessment are not mentioned at all. The media coverage considered, if anything, environmental issues such as environment protection or environmental cleanup (2\%).

There is a significant relationship between the representation of scientific uncertainty and risks $\left(\chi^{2}(d f 1)=91.551\right.$, $p<.001 ; \Phi=.67)$. Scientific uncertainty primarily arises from unknown harmful effects to human health (58\%) and the environment (31\%). These risks are mentioned in a very general way and their causes are rarely described in detail.

\section{Coverage patterns of scientific uncertainty in different media types \\ Newspapers}

Newspaper coverage can be differentiated into three cluster types: 'benefit of nanotechnology application' ( $n=104$,

Table 5 Coverage patterns of scientific uncertainty in the media

\begin{tabular}{lll}
\hline Newspapers & Science journals & TV science magazines \\
\hline $\begin{array}{l}\text { Benefit of } \\
\text { nanotechnology }\end{array}$ & $\begin{array}{l}\text { Benefit of } \\
\text { nanotechnology } \\
(n=27,100 \%)\end{array}$ & $\begin{array}{l}\text { Benefit and scientific } \\
\text { certainty of } \\
\text { nanotechnology } \\
\text { applications }(n=21,64 \%)\end{array}$ \\
$\begin{array}{l}\text { Benefit and scientific } \\
\text { certainty of }\end{array}$ & $\begin{array}{l}\text { Ambivalence about } \\
\text { nanotechnology research } \\
(n=22,15 \%)\end{array}$ & $\begin{array}{l}\text { risks }(n=12,36 \%) \\
\text { Political discourse about } \\
\text { scientific uncertainty and } \\
\text { risks }(n=18,13 \%)\end{array}$ \\
\hline
\end{tabular}

$72 \%)$, 'benefit and scientific certainty of nanotechnology research' $(n=22,15 \%)$, and 'political discourse about scientific uncertainty and risks' ( $n=18,13 \%)$.

Type 1: 'benefit of nanotechnology applications' $(n=104$, $72 \%)$. This cluster is characterized by articles concerning the applications of nanotechnology. The most frequently mentioned application topics are nanomedicine (21\%), information and communication technologies (14\%), and energy technology (11\%). In comparison with the other clusters, environmental topics such as environment protection or environmental remediation appear above average frequency. This cluster emphasizes the benefits of nanotechnology applications for human health and the environment and includes positive assessments (65\%), whereas risks are barely mentioned (6\%). Scientific uncertainty and certainty also rarely appear.

Type 2: 'benefit and scientific certainty of nanotechnology research' ( $n=22,15 \%)$. In this cluster, the topic basic research is the focus. Scientific certainty is founded on unambiguous research findings (59\%); however, there are also a fair number of scientific uncertainties (27\%), which are founded on the unknown effects on human health and the environment. Furthermore, the benefits of nanotechnology are strongly highlighted (91\%) due to improved material properties, and risks are essentially justified by unknown harmful effects on human health and the environment (23\%).

Type 3: 'political discourse about scientific uncertainty and risks' ( $n=18,13 \%)$. The third cluster is characterized by its above-average presentation of political and ethical aspects of nanotechnology, risks, and scientific uncertainty. Scientific uncertainties are strongly highlighted (94\%), and they are caused by the unknown harmful effects of nanoparticles on human health $(89 \%)$ and the environment (50\%). The contention is that nanoparticles are able to cross the human body to invade organs or tissues such as the brain, heart, or nervous system. Therefore, about $72 \%$ of the assessments by politicians and public agencies are negative. As a result, the articles in this cluster ask for risk regulation (44\%), continuation of the research (39\%), furthering of the public dialogue (28\%), and more economic investments (17\%).

Science journals: 'benefit of nanotechnology' ( $n=27,100 \%)$ Science magazines were not further classified because they represent the nanotechnology topics in a homogenous way. All in all, the media reports in science magazines can be summarized under the label 'benefit of nanotechnology'. The topics are nanotechnology research (56\%) as well as nanotechnology applications (44\%) such as energy management and nanomedicine. The tenor of the reports is positive because benefits are emphasized (74\%) and about $67 \%$ of positive assessments and only $4 \%$ of negative assessments are 
mentioned. The majority of the reports represents scientific certainty (78\%) and justified this by depicting unambiguous research results. Responsible actors for scientific certainty are scientists.

\section{TV science magazines}

The result of the cluster analysis of TV science magazines resulted in two cluster types: 'benefit and scientific certainty of nanotechnology applications' ( $n=21,64 \%)$ and 'ambivalence about scientific evidence and risks' ( $n=12,36 \%)$.

Type 1: 'benefit and scientific certainty of nanotechnology applications' ( $n=21,64 \%)$. This cluster is characterized by reports concerning the applications of nanotechnology. Benefits such as health and environmental benefits appear above average and are frequently highlighted (91\%). Furthermore, positive assessments are emphasized (62\%), whereas risks are scarcely dealt with (14\%). Scientific certainties are emphasized (62\%) and they are caused by unambiguous research results. However, there are also a fair number of scientific uncertainties (29\%).

Type 2: 'ambivalence about scientific evidence and risks' ( $n=12,36 \%)$. In this cluster, the main topics are nanotechnology applications (50\%) and nanotechnology research (25\%) as well as politics and nanotechnology (17\%), while the political issues are represented above average. The depiction of scientific uncertainties and scientific certainty is balanced and both are strongly emphasized (the frequency of each is $92 \%$ ). The causes for scientific uncertainty are founded on the unknown effects on human health and environment, whereas scientific certainty is justified by depicting unambiguous research results. Scientists, public agencies, and nongovernmental organizations are the main argument sources. The tone of the reports is mainly negative because the unknown harmful effects on human health and environment are stressed above average and the assessments are primarily negative (83\%). Similarly to the newspaper cluster type 3, the reports in this cluster ask for risk regulation (42\%), furthering of the public dialogue (33\%), and continuation of the research (25\%).

In summary, the central findings of the media content analysis are that nanotechnology is often framed as rather certain and the media coverage emphasizes positive aspects and benefits. These results are in line with previous studies $[24,27,33]$. The main topics are basic research and nanomedicine, whereas environment topics are seldom mentioned. Furthermore, the study shows that only about one-third of the media coverage deals with scientific uncertainty. There is a strong relationship between the representations of scientific uncertainty and risks. This corresponds with the results form Friedman and Egolf [24]. Scientific uncertainty is often justified by unknown harmful effects on human health and the environment, while other reasons are only rarely presented. It appears that the causes of scientific uncertainty are stated in a rather general manner, while scientific certainty is more scientifically based, e.g., by unambiguous research findings. The cluster analyses show that there are differences between the three analyzed media types. Both newspapers and TV science magazines make scientific uncertainty a subject of discussion, whereas science journals do not. In contrast to the two other media, science journals represent nanotechnology predominantly in a positive and scientificbased way. TV science magazines emphasize scientific uncertainty in relation more than twice as often as newspapers do. The science coverage in newspapers emphasizes political issues more often, whereas in TV science magazines the pros and cons of nanotechnology are frequently under discussion. These differences can be explained by the aims of the media. While science journals address a special-interest target group interested in science, newspapers report more often on current scientific topics and news with a political and/or societal link. In contrast to science journals and newspapers, TV science magazines frequently cover background information or explain current scientific issues. Therefore, the representation of scientific evidence with scientific uncertainty or certainty is of particular interest.

\section{Comparing research literature and mass media}

In the selected original research papers, uncertainties of their own research results were not explicitly mentioned. Zehr stated that scientists in peer-reviewed articles often remove contingencies from their statements [63]. This leads to the perception of more certainty [63], which could also be the case here. The uncertainties most often discussed were related to the transferability of the results to environmental conditions. This seemed comprehensible: in the field of nanoparticle mobility in porous media, one focus of current research is transport mechanisms, which are studied in model systems with a limited number of influencing factors. There is always uncertainty about transferring the results of such model systems to environmental conditions because of the high amounts of influencing factors in the real environment. In contrast to the review articles, the lack of data was not discussed in the research articles related to their own research results. This is also comprehensible: the task of research papers is to provide new findings. If their own research provided a lack of data, it would not be published.

The task of a review paper is to summarize and analyze already published data. This includes the detection and discussion of uncertainties and knowledge gaps. Therefore, uncertainties related to general topics and to specific mechanisms and effects as well as sources and consequences of these uncertainties were discussed and detailed in the review articles much more frequently than in the research papers. The questionable transferability of results to environmental conditions discussed in the research 
papers was possibly not explicitly discussed in the review papers because the conclusions were drawn that the results were not transferable to environmental conditions or there were not enough data, or because the behavior in environmental conditions was identified as a knowledge gap.

In summary, in research papers, the authors focused more on the certainty of specific results, whereas in review papers, the uncertainty due to a general lack of data was emphasized and the sources and consequences were discussed. This different emphasis (on the certainty of single results and on the uncertainty in the summarizing reviews) may result in an inconsistent picture of the (un) certainty in the research on the environmental fate of nanoparticles, which may open up room for different interpretations.

Looking across all of the investigated media coverage, the results of the content analysis show that the science coverage was more focused on nanotechnology applications than on nanotechnology research, and in the context of nanotechnology applications, journalists emphasized scientific certainty, which was caused by unambiguous research results. In sum, the media coverage about nanotechnology has been predominantly positive and optimistic in tone. The scientific uncertainty of nanotechnology research was less frequently mentioned and it was predominantly associated with political aspects and risks. Furthermore, scientists as well as politicians, NGOs, and government bodies are the main actors. This implies that the communication of scientific uncertainty plays a role in the relationship with public political discourses rather than with media coverage about scientific issues. Hence, detailed scientific justifications, e.g., the lack of data, conflicting results, and method or measurement uncertainties, were often missed. In sum, media coverage represents neither the broad spectrum nor any specifications of scientific uncertainties.

These results are in line with previous research findings of science journalist questioning. Günther and Ruhrmann [64] showed that journalistic perception of uncertainty varies according to the nanotechnology topic they cover. Only journalists reporting risks perceived research findings as being uncertain. However, most journalists favored topics related to applications of nanotechnology because they are directly combined with the consumer needs of their audience. They believe that the audience is more interested in nanotechnology applications than in basic research findings with the result that the media coverage about uncertainties in nanotechnology research is unbalanced and brief [65].

\section{Conclusions}

In research and review papers as well as in mass media reports, scientific uncertainties have been mentioned with different foci, different degrees of abstraction, and to different extents. Scientific uncertainties, sources, and consequences were most widely discussed in review papers, whereas research papers and mass media tend to emphasize more the certainty of their results or topics, and neither the broad spectrum nor further specifications like sources or consequences of uncertainties were communicated. Furthermore, our results suggest that scientific uncertainty in mass media is predominantly communicated in relation to political issues and risks and not particularly in relation to research results in general and environmental research in particular. This indicates that there has been no effective dialogue about scientific uncertainty in environmental research with the public so far [66].

These findings concerning communication about uncertainties are not solely valid for nanotechnology but also for other research fields of emerging technologies such as biotechnology and genetic engineering. However, the predominant positive reporting in the mass media under such fundamental scientific uncertainties is specific for the field of nanotechnology. Some reasons may be the tremendously wide range of applications of nanotechnology, the absence of a single negative outstanding event like the birth of the cloned sheep 'Dolly' in 1998, or societal and political discourses about ethical problems like embryonic stem cell research.

Six years after its publication, the statement from Nowack and Bucheli from 2007 that 'the public discussion predates the possibility of their analysis' is still true [59], but this simple and clear fact is not communicated to the public. In summary, neither the uncertainties, sources, and consequences nor even the topics of the research concerning the environmental fate and effects of nanoparticles are making their way into the mass media. If uncertainty is only communicated in relation to risks, there may be a possibility of a public reaction similar to the highly critical public debate about modern biotechnology in Germany [64].

\section{Methods}

\section{Meta-analysis of research and review papers}

To characterize the scientific uncertainties in the field of the environmental fate of nanoparticles, a meta-analysis of original research papers concerning the aspect 'transport of metal oxide nanoparticles in porous media' was conducted as described in Heidmann [38]. This constricted topic was chosen in order enable the comparison of the discussion on the different mentioned uncertainties in one research field. The topic was chosen because mobility is one of the most important factors which determine the fate and effects of a substance in the environment, e.g., if a substance is highly mobile, it is probable that it can reach other compartments (rivers, soil, groundwater, and plants) or regions after release into the environment and cause unwanted effects there. The literature was screened in March 
2012 for peer-reviewed original research articles dealing with experiments in the abovementioned field. Searches were carried out in the Web of Science with search terms like 'nano"*, 'transport,' 'deposition', 'porous media', and 'soil'. Searching for the term 'nano" (transport or mobility or retention) in the article topic, together with the term 'porous media, leads to over 600 results and, together with the term 'soil', to around 400 results. These articles were scanned for research papers dealing with metal oxide nanoparticle transport in water-saturated porous media like glass beads, sand, or soil material, and only one paper per first author was selected. After this specification, 13 papers were left for the meta-analysis, which are shown in Table 1.

To conduct a meta-analysis concerning the scientific uncertainties in the field 'environmental fate of nanoparticles' in review papers, a literature search was conducted in January 2013 for review articles dealing with this topic. Searches were carried out in the Web of Science with search terms like 'review, 'nano', 'environment,' 'fate,' 'effect,' 'behavior', and 'impact'. Searching for the terms 'review,' 'nano', 'environment', and 'fate,' 'effect,',behavior', or 'impact' in the article topic leads to over 860 results. In order to achieve the right abstraction level and comparable issues, these articles were scanned for relevant reviews dealing with several types of nanoparticles, occurrence, fate, behavior, or effects in the environment. Reviews with emphasis on toxicology, analytical methods, life cycle, or risk assessment were not considered, and only one paper per first author was selected. Articles were considered as relevant if the article was cited at least eight times according to the Web of Science. After this specification, nine reviews were left for the meta-analysis, which are shown in Table 3.

The meta-analyses were carried out concerning the following topics: measurement uncertainties, conflicting results, method uncertainty, lack of data, transferability to environmental conditions, transferability to other nanoparticles, applicability of models, knowledge gaps, sources of uncertainty, and consequences of uncertainty. Topics mentioned as research needs were categorized as 'lack of data'. Every paper was counted only once per specification, even if these specifications were mentioned more often.

\section{Content analysis of media coverage}

To answer the research questions, a quantitative content analysis of the media coverage about nanotechnology in newspapers, science magazines, and TV science magazines was conducted.

\section{Sample}

The content analysis is based on a full-sample survey and includes nanotechnology stories published in the period 2010 to 2011 in Germany. The population was identified by searching the online archives of the TV broadcasts and the newspaper database 'Genios' (www. genios.de). To examine the thematic content, we used thematic keywords. The TV clips in 2010 became available through the TV broadcasts, and in 2011, we recorded the current TV program. We identified 439 articles in the newspapers, 27 articles in science magazines, and 33 clips in TV science magazines. To analyze science coverage in the newspapers, we selected a representative sample of 144 articles (see Table 6).

\section{Coding and analysis}

A coding scheme with relevant categories was generated. It includes the main categories 'scientific uncertainty/ certainty' and 'risks and benefits of nanotechnology', and judgmental variables such as assessments, forecasts, and treatment recommendations. Furthermore, topics and actors have been collected.

We defined the operationalization of the variables based on the definition of scientific uncertainty at the beginning of this paper. To investigate the representation of scientific uncertainty, we differentiate between the depiction of implicit and explicit scientific uncertainty/certainty because journalists are able to represent uncertainty/certainty in a specific or in an indirect way.

Table 6 Sample reports

\begin{tabular}{|c|c|c|}
\hline Newspapers $(n=144)$ & Science magazines $(n=27)$ & TV science magazines $(n=33)$ \\
\hline Süddeutsche Zeitung & Bild der Wissenschaft & Wissen vor 8 (ARD/Das Erste) \\
\hline FAZ & P.M. Magazin & W wie Wissen (ARD/Das Erste) \\
\hline $\operatorname{taz}$ & Spektrum der Wissenschaft & Im Grünen (SWR) \\
\hline Frankfurter Rundschau & Natur und Kosmos & Planet Wissen (SWR) \\
\hline Die Zeit & & Odysso (SWR) \\
\hline Die Welt & & Plietsch (NDR) \\
\hline Welt am Sonntag & & Alles wissen (HR) \\
\hline \multirow[t]{2}{*}{ Frankfurter Allgemeine Sonntagszeitung } & & Nano (3sat) \\
\hline & & X:enius (arte) \\
\hline
\end{tabular}


To determine the explicitly verbalized scientific uncertainty/ certainty, we used variables such as 'lack of data/sufficient data,' contradictory data/unambiguous data', and 'traceability/ non-traceability of measurement'. The implicitly verbalized scientific uncertainty/certainty was investigated by linguistic characteristics of the German language such as using the subjunctive. To operationalize risk and benefit as well as judgment variables, we used previous theoretical considerations and studies [33,67]. The risk/benefit variables are variables about the representation of risk and benefit, as well as risk/benefit expectations and risk/benefit causes. Furthermore, assessments, demands, forecasts, and recommendations were compiled. The variables orientate along the 'W questions' (e.g., who, when, what, where, why, etc.), which are used especially in journalistic presentations such as news or reports. Additionally, topics, actors, and formal information (e.g., publication date, placement, and duration) were compiled. Each TV clip and article was analyzed by three coders using the coding scheme. The total intercoder reliability for all of the variables is $R=0.90$.

To identify the coverage patterns, a hierarchical cluster analysis with the important variables 'scientific uncertainty/certainty' and 'risks/benefits' as well as 'topics' was conducted. For hierarchical cluster analysis, we applied the Ward method, and for distance measure, we used the squared Euclidean distance method. For this purpose, the variables were dichotomized. To determine the cluster, homogenous $F$ and $t$ values were calculated. For the description of the clusters, descriptive variables were considered.

\section{Competing interests}

Both authors declare that they have no competing interests.

\section{Authors' contributions}

$\mathrm{IH}$ designed and performed the meta-analysis with the research and review papers and drafted the respective parts of the manuscript. JM designed and performed the content analysis of the media coverage and drafted the respective parts of the manuscript. Both authors drafted together the overlapping background, comparing discussion and the conclusions, and read and approved the final manuscript.

\section{Acknowledgements}

The authors are grateful for financial support by the Ministry for Education, Sciences, Further Education and Culture of the State of Rhineland-Palatinate (MBWWK) and the German Research Foundation (DFG).

Received: 7 May 2013 Accepted: 1 August 2013

Published: 22 August 2013

\section{References}

1. Piccinno F, Gottschalk F, Seeger S, Nowack B: Industrial production quantities and uses of ten engineered nanomaterials in Europe and the world. J Nanopart Res 2012, 1109:1-11.

2. Benn T, Cavanagh B, Hristovski K, Posner JD, Westerhoff P: The release of nanosilver from consumer products used in the home. J Environ Qual 2010, 39:1875-1882.

3. Benn TM, Westerhoff P: Nanoparticle silver released into water from commercially available sock fabrics. Environ Sci Technol 2008, 42:4133-4139.
4. Botta C, Labille J, Auffan M, Borschneck D, Miche H, Cabie M, Masion A, Rose J, Bottero $\mathrm{JY}_{\text {: }} \mathrm{TiO}_{2}$-based nanoparticles released in water from commercialized sunscreens in a life-cycle perspective: structures and quantities. Environ Pollut 2011, 159:1543-1548.

5. Gottschalk F, Nowack B: The release of engineered nanomaterials to the environment. J Environ Monit 2011, 13:1145-1155.

6. Kaegi $R$, Sinnet B, Zuleeg $S$, Hagendorfer H, Mueller E, Vonbank R, Boller M, Burkhardt M: Release of silver nanoparticles from outdoor facades. Environ Pollut 2010, 158:2900-2905.

7. Kiser MA, Westerhoff P, Benn T, Wang Y, Perez-Rivera J, Hristovski K: Titanium nanomaterial removal and release from wastewater treatment plants. Environ Sci Technol 2009, 43:6757-6763.

8. Nowack B, Ranville JF, Diamond S, Gallego-Urrea JA, Metcalfe C, Rose J, Horne N, Koelmans AA, Klaine SJ: Potential scenarios for nanomaterial release and subsequent alteration in the environment. Environ Toxicol Chem 2012, 31:50-59.

9. Lowry GV, Hotze EM, Bernhardt ES, Dionysiou DD, Pedersen JA, Wiesner MR, Xing BS: Environmental occurrences, behavior, fate, and ecological effects of nanomaterials: an introduction to the special series. J Environ Qual 2010, 39:1867-1874.

10. Som C, Berges M, Chaudhry Q, Dusinska M, Fernandes TF, Olsen SI, Nowack B: The importance of life cycle concepts for the development of safe nanoproducts. Toxicology 2010, 269:160-169.

11. Klaine SJ, Koelmans AA, Horne N, Carley S, Handy RD, Kapustka L, Nowack B, von der Kammer F: Paradigms to assess the environmental impact of manufactured nanomaterials. Environ Toxicol Chem 2012, 31:3-14.

12. Kwon SY, Kim YG, Lee SH, Moon JH: Uncertainty analysis of measurements of the size of nanoparticles in aqueous solutions using dynamic light scattering. Metrologia 2011, 48:417-425.

13. Wagner R, Moon R, Pratt J, Shaw G, Raman A: Uncertainty quantification in nanomechanical measurements using the atomic force microscope. Nanotechnology 2011, 22:455703.

14. Grieger KD, Hansen SF, Baun A: The known unknowns of nanomaterials: describing and characterizing uncertainty within environmental, health and safety risks. Nanotoxicology 2009, 3:1-U17.

15. Einsiedel EF, Thorn B: Public responses to uncertainty. In Communicating Uncertainty: Media Coverage of New and Controversial Science. Edited by Friedman SM, Dunwoody S, Rogers CL. Mahwah: Lawrence Erlbaum; 1999:43-57.

16. Nelkin D: Selling Science: How the Press Covers Science and Technology. New York: W. H. Freeman; 1995.

17. Cobb MD: Framing effects on public opinion about nanotechnology. Sci Commun 2005, 27:221-239.

18. Kahan DM, Braman D, Slovic P, Gastil J, Cohen GL: Cultural cognition of the risks and benefits of nanotechnology. Nat Nanotechnol 2009, 4:87-91.

19. Retzbach A, Marschall J, Rahnke M, Otto L, Maier M: Public understanding of science and the perception of nanotechnology: the roles of interest in science, methodological knowledge, epistemological beliefs, and beliefs about science. J Nanopart Res 2011, 13:6231-6244.

20. Ho S, Scheufele D, Corley E: Making sense of policy choices: understanding the roles of value predispositions, mass media, and cognitive processing in public attitudes toward nanotechnology. J Nanopart Res 2010, 12:2703-2715.

21. Anderson A, Allan S, Petersen A, Wilkinson C: The framing of nanotechnologies in the British newspaper press. Sci Commun 2005 27:200-220.

22. Boholm M, Boholm A: The many faces of nano in newspaper reporting. J. Nanopart. Res. 2012, 14:722-740.

23. Dudo A, Dunwoody S, Scheufele DA: The emergence of nano news: tracking thematic trends and changes in U.S. newspaper coverage of nanotechnology. Journalism Mass Comm 2011, 88:55-75.

24. Friedman SM, Egolf BP: A longitudinal study of newspaper and wire service coverage of nanotechnology risks. Risk Anal 2011, 31:1701-1717.

25. Groboljsek B, Mali F: Daily newspapers' views on nanotechnology in Slovenia. Sci Commun 2012, 34:30-56

26. Kjærgaard RS: Making a small country count: nanotechnology in Danish newspapers from 1996 to 2006. Public Underst Sci 2010, 19:80-97.

27. Kjølberg KL: Representations of nanotechnology in Norwegian newspapers - implications for public participation. Nano Ethics 2009, 3:61-72.

28. Weaver DA, Lively E, Bimber B: Searching for a frame: news media tell the story of technological progress, risk, and regulation. Sci Commun 2009, 31:139-166 
29. Wilkinson C, Allan S, Anderson A, Petersen A: From uncertainty to risk?: Scientific and news media portrayals of nanoparticle safety. Health Risk Soc 2007, 9:145-157

30. Lewenstein BV, Gorss J, Radin J: ICA 2005: Communication: Questioning the Dialogue. 55th Annual Conference of the International Communication Association: 26-30 May 2005; New York City.

Washington, D.C: ICA; 2005

31. Cacciatore MA, Anderson AA, Choi D-H, Brossard D, Scheufele DA, Liang X, Ladwig PJ, Xenos M, Dudo A: Coverage of emerging technologies: a comparison between print and online media. New Media Soc 2012, 14:1039-1059.

32. Fitzgerald S: Constructing risk: media coverage of nanotechnology. In ASA 2007: 102nd Annual Meeting of the American Sociological Association: August 2007; New York City. Washington, D.C: ASA; 2007.

33. Donk A, Metag J, Kohring M, Marcinkowski F: Framing emerging technologies: risk perceptions of nanotechnology in the German press. Sci Commun 2012, 34:5-29.

34. Stephens LF: News narratives about nano s\&t in major U.S. and non-U.S. newspapers. Sci Commun 2005, 27:175-199.

35. Petersen A, Anderson A, Wilkinson C, Allan S: Nanotechnologies, risk and society. Health Risk Soc 2007, 9:117-124.

36. Grobe A, Eberhard C, Hutterli M: Nanotechnologie im Spiegel der Medien: Medienanalyse zur Berichterstattung über Chancen und Risiken der Nanotechnologie. St. Gallen: Stiftung Risiko-Dialog; 2005.

37. Friedman SM, Egolf BP: Nanotechnology: risks and the media. IEEE Technol Soc Mag 2005, 24:5-11.

38. Heidmann I: Metal oxide nanoparticle transport in porous media - an analysis about (un)certainties in environmental research. $J$ Phys Conf Ser 2013, 429:012042 (1-10)

39. Commission E: Scientific Research in the Media. Special Eurobarometer 282: TNS Opinion \& Social. Brüssel: European Commission; 2007.

40. Ben-Moshe T, Dror I, Berkowitz B: Transport of metal oxide nanoparticles in saturated porous media. Chemosphere 2010, 81:387-393.

41. Chen GX, Liu XY, Su CM: Transport and retention of $\mathrm{TiO}_{2}$ rutile nanoparticles in saturated porous media under low-ionic-strength conditions: measurements and mechanisms. Langmuir 2011, 27:5393-5402.

42. Chowdhury I, Hong Y, Honda RJ, Walker SL: Mechanisms of $\mathrm{TiO}_{2}$ nanoparticle transport in porous media: role of solution chemistry, nanoparticle concentration, and flowrate. J Colloid Interface Sci 2011, 360:548-555.

43. Fang J, Shan XQ, Wen B, Lin JM, Owens G: Stability of titania nanoparticles in soil suspensions and transport in saturated homogeneous soil columns. Environ Pollut 2009, 157:1101-1109.

44. Godinez IG, Darnault CJG: Aggregation and transport of nano-TiO ${ }_{2}$ in saturated porous media: effects of $\mathrm{pH}$, surfactants and flow velocity. Water Res 2011, 45:839-851.

45. Jiang XJ, Tong MP, Lu RQ, Kim H: Transport and deposition of $\mathrm{ZnO}$ nanoparticles in saturated porous media. Colloids Surf., A 2012, 401:29-37.

46. Joo SH, Al-Abed SR, Luxton T: Influence of carboxymethyl cellulose for the transport of titanium dioxide nanoparticles in clean silica and mineralcoated sands. Environ Sci Technol 2009, 43:4954-4959.

47. Kanel SR, Al-Abed SR: Influence of $\mathrm{pH}$ on the transport of nanoscale zinc oxide in saturated porous media. J Nanopart Res 2011, 13:4035-4047.

48. Lecoanet HF, Bottero JY, Wiesner MR: Laboratory assessment of the mobility of nanomaterials in porous media. Environ Sci Technol 2004 38:5164-5169.

49. Li Z, Sahle-Demessie E, Hassan AA, Sorial GA: Transport and deposition of $\mathrm{CeO}_{2}$ nanoparticles in water-saturated porous media. Water Res 2011 , 45:4409-4418

50. Petosa AR, Brennan SJ, Rajput F, Tufenkji N: Transport of two metal oxide nanoparticles in saturated granular porous media: role of water chemistry and particle coating. Water Res 2012, 46:1273-1285.

51. Solovitch N, Labille J, Rose J, Chaurand P, Borschneck D, Wiesner MR, Bottero JY: Concurrent aggregation and deposition of $\mathrm{TiO}_{2}$ nanoparticles in a sandy porous media. Environ Sci Technol 2010, 44:4897-4902.

52. Zhao LJ, Peralta-Videa JR, Hernandez-Viezcas JA, Hong J, Gardea-Torresdey $J$ : Transport and retention behavior of $\mathrm{ZnO}$ nanoparticles in two natural soils: effect of surface coating and soil composition. J. Nano Res. 2012, 17:229-242.

53. Aschberger K, Micheletti C, Sokull-Kluttgen B, Christensen FM: Analysis of currently available data for characterising the risk of engineered nanomaterials to the environment and human health - lessons learned from four case studies. Environ Int 2011, 37:1143-1156.

54. Christian P, Von der Kammer F, Baalousha M, Hofmann T: Nanoparticles: structure, properties, preparation and behaviour in environmental media. Ecotoxicology 2008, 17:326-343.

55. Farre M, Sanchis J, Barcelo D: Analysis and assessment of the occurrence, the fate and the behavior of nanomaterials in the environment. TrAC Trends Anal Chem 2011, 30:517-527.

56. Klaine SJ, Alvarez PJJ, Batley GE, Fernandes TF, Handy RD, Lyon DY, Mahendra S, McLaughlin MJ, Lead JR: Nanomaterials in the environment: behavior, fate, bioavailability, and effects. Environ Toxicol Chem 2008, 27:1825-1851.

57. Lin DH, Tian XL, Wu FC, Xing BS: Fate and transport of engineered nanomaterials in the environment. J Environ Qual 2010, 39:1896-1908.

58. Mudunkotuwa IA, Grassian VH: The devil is in the details (or the surface): impact of surface structure and surface energetics on understanding the behavior of nanomaterials in the environment. J Environ Monit 2011 13:1135-1144

59. Nowack B, Bucheli TD: Occurrence, behavior and effects of nanoparticles in the environment. Environ Pollut 2007, 150:5-22.

60. Peralta-Videa JR, Zhao LJ, Lopez-Moreno ML, de la Rosa G, Hong J, Gardea-Torresdey JL: Nanomaterials and the environment: a review for the biennium 2008-2010. J Hazard Mater 2011, 186:1-15.

61. von der Kammer F, Ferguson PL, Holden PA, Masion A, Rogers KR, Klaine SJ, Koelmans AA, Horne N, Unrine JM: Analysis of engineered nanomaterials in complex matrices (environment and biota): general considerations and conceptual case studies. Environ Toxicol Chem 2012, 31:32-49.

62. Tiede K, Boxall ABA, Tear SP, Lewis J, David H, Hassellov M: Detection and characterization of engineered nanoparticles in food and the environment. Food Addit Contam 2008, 25:795-821.

63. Zehr SC: Scientists' representations of uncertainty. In Communicating Uncertainty: Media Coverage of New and Controversial Science. Edited by Friedman SM, Dunwoody S, Rogers CL. Mahwah: Lawrence Erlbaum; 1999:3-21.

64. Günther L, Ruhrmann G: Science journalists' selection criteria and depiction of nanotechnology in German media. In ICA 2013: Challenging Communication Research. 63rd Annual Conference of the International Communication Association: June 2013; London. Washington, D.C: ICA; 2013.

65. Ebeling MFE: Mediating uncertainty: communicating the financial risks of nanotechnologies. Sci Commun 2008, 29:335-361.

66. Pidgeon N, Harthorn B, Satterfield T: Nanotechnology risk perceptions and communication: emerging technologies, emerging challenges. Risk Anal 2011, 31:1694-1700.

67. Milde J, Ruhrmann G: Molekulare Medizin in deutschen TVWissenschaftsmagazinen. Ergebnisse von Journalisteninterviews und Inhaltsanalysen. Medien \& Kommunikationswissenschaft 2006, 54:430-456.

doi:10.1186/2190-4715-25-25

Cite this article as: Heidmann and Milde: Communication about scientific uncertainty: how scientists and science journalists deal with uncertainties in nanoparticle research. Environmental Sciences Europe $201325: 25$

\section{Submit your manuscript to a SpringerOpen ${ }^{\circ}$ journal and benefit from:}

- Convenient online submission

- Rigorous peer review

- Immediate publication on acceptance

- Open access: articles freely available online

- High visibility within the field

- Retaining the copyright to your article

Submit your next manuscript at $>$ springeropen.com 